\title{
Use of Sphenopalatine Ganglion Blockade in Chronic Migraine Management
}

\author{
Kaitlin Krebs and X Michelle Androulakis* \\ Department of Neurology, University of South Carolina, USA
}

Submission: May 06, 2017; Published: July 31, 2017

*Corresponding author: Michelle Androulakis X, University of South Carolina, Department of Neurology Medical Park Road, Suite 420 Columbia, SC 29203, USA, Tel: 803-545-6050; Fax: 803-545-6066; Email: Michelle.Androulakis@uscmed.sc.edu

\section{Case Report}

Chronic migraine (CM) is a debilitating neurological disorder which affects more than 4 million individuals in the United State and $2 \%$ of the global population [1] in 2015, the Health Care utilization was estimated at $\$ 5.4$ billion and the total cost associated with management of comorbidities exceeded over $\$ 40$ billion in united states [2,3]. Different acute and preventive therapies, which are available for chronic migraineurs, are generally sub-optimally effective and are accompanied by side effects that are difficult to tolerate. Currently, Botulinum toxin therapy (Botox) is the only FDA approved CM preventative therapy, however, it is expensive and up to $9 \%$ of patients experience side effects such as neck pain after the injections. Recently, SPG neuromodulation has gained interest among headache specialist in management of CM. A series of SPG blockade using intranasal bupivacaine was efficacious for acute pain reduction in CM. However, further investigation into the long term preventative benefit of SPG block is warranted as this study sample size was too small to reach its statistical significance $[4,5]$.

Sphenopalatine ganglion (SPG) has been a very important target for headache management since the beginning of the 20th century. SPG is the largest extra cranially ganglion of the head and is likely to play an important role in migraine pathogenesis through the activation of trigemino-autonomic reflex [6]. Up to $70 \%$ of migraine patients have cranial autonomic symptoms such as eyelid edema, nasal congestion, lacrimation, conjunctival injection, rhinorrhea, and facial swelling [7]. SPG modulation via electrical stimulation, microvascular decompression, surgical or radiofrequency ablation, and radiosurgical lesion have been performed for head pain in operating room settings, however, adverse effects of these interventions can be extensive. The SPG is located just posterior/superior to the tail of the middle turbinate on the lateral nasal wall and superior to the pterygopalatine fossa.
Manipulation of this region was often very challenging, as there is no direct access to the SPG and it is covered by a thin layer of nasal mucosa $(1-1.5 \mathrm{~mm})$. New methods to modulate the SPG with a topical, intranasal approach have proven to be among the safest, least invasive, and least costly of all SPG interventions in headache management.

Recently, several new devices have been developed which facilitate a more accurate and effective delivery of the local anesthetics into the SPG. The risks of this procedure are typically minimal and may include minor discomfort during and after the procedure, a numbing or burning sensation, bitter taste from the anesthesia, bleeding from the nose (rarely), and lightheadedness. These side effects typically resolve within minutes to a few hours. There is also a very small risk of allergic reactions.

Use of SPG block has been recommended by American Headache Society (AHS) as part of comprehensive headache management plan. Indeed, repetitive SPG blockade twice a week for 6 weeks provides an alternative migraine prophylaxis for those with chronic migraine but could not tolerate (i.e. needle phobia) or unresponsive to Botox therapy. SPG block generally provides a better outcome for treatment of CM with head pain in frontal and/orbital regions, and may also help CM patients with coexisting medication overuse headaches to wean off excessive use of pain medications.

Nausea, which has been suggested as one of the main contributing factors for migraine chronification, is also another possible symptom that can be relieved with a series of SPG block. The area postrema area, located at the infer posterior part of IV ventricle, is responsible for nausea and vomiting through its connection to the nucleus of the solitary tract. The superior salivatory nucleus (SSN) provides preganglionic parasympathetic innervation to SPG, but also receives inputs from multiple areas, such as nucleus of solitary tract, limbic, 
and cortical regions. Repetitive intranasal SPG blockade with bupivacaine may reduce nausea and vomiting via inhibition of superior salivatory nucleus given its direct connection with the nucleus of solitary tract.

The exact mechanism of SPG neuro modulation remains to be elucidated. It has been postulated that inhibition of the parasympathetic outflow from the SPG would inhibit pain and autonomic symptoms that accompanying recurrent migraine attacks. This inhibition of parasympathetic outflow would decrease activation of perivascular nociceptors in the cranial and meningeal vasculature, especially in the frontal regions of the brain [8-10]. Additionally, modulation of the SPG may in turn modulate brain networks activity involved in pain processing. In a recent resting state functional MRI connectivity study, our group demonstrated that a series of SPG block treatment in chronic migraine significantly improved two intrinsic resting state functional connectivity networks (manuscript in preparation). This increase in functional connectivity coherence may represent that after effective treatment, reorganization of resting state brain networks to normalized states may occur.

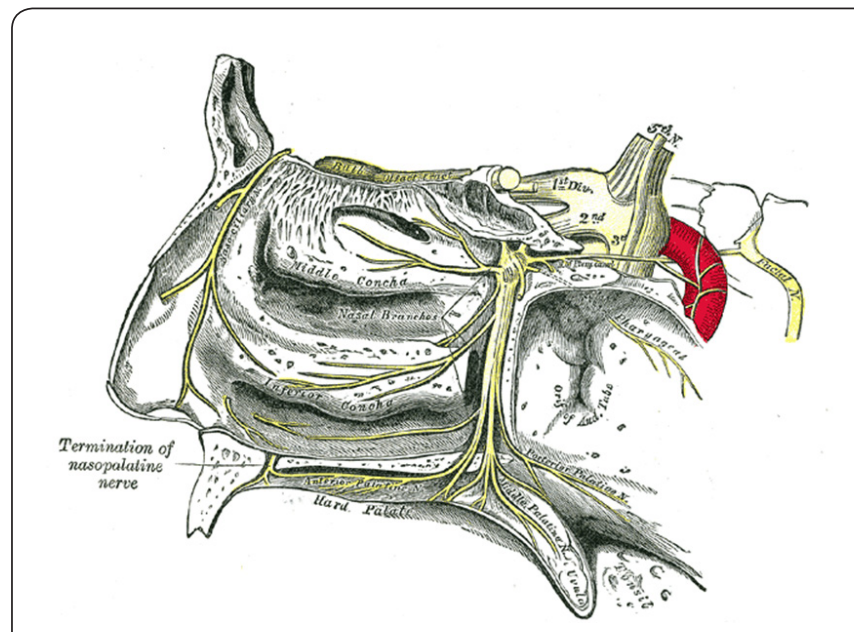

Figure 1: Anatomical illustration of the Sphenopalatine Ganglion (circled in black) and its relationship with CN V and VII.

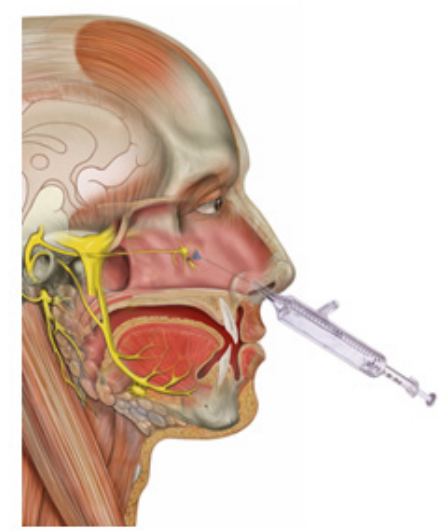

Figure 2: Illustration of the administration of the Sphenopalatine Ganglion block using Marcaine.
Additionally, reduced parasympathetic outflow due to repetitive SPG inhibition may help to restore baseline homeostasis of brain networks involved in pain processing, via improved mesocorticolimbic modulation [11-13]. A large double blinded, randomized, placebo controlled clinical trial is warranted to evaluate the efficacy of repetitive SPG block in CM (Figure $1 \& 2$ ).

\section{References}

1. Natoli JL (2010) Global Prevalence of Chronic Migraine: A Systematic Review Cephalalgia. An international journal of headache 30(5): 599609.

2. Dodick David W (2016) Assessing Barriers to Chronic Migraine Consultation, Diagnosis, and Treatment: Results From the Chronic

Migraine Epidemiology and Outcomes (CaMEO) Study. Headache. doi: 10.1111/head.12774.

3. Lipton Richard B (2016) A Comparison of the Chronic Migraine Epidemiology and Outcomes (CaMEO) Study and American Migraine Prevalence and Prevention (AMPP) Study: Demographics and Headache-Related Disability Headache 56(8): 1280-1289.

4. Cady RK, Saper J, Dexter K, Cady RJ, Manley HR (2015) A Double-Blind, Placebo-Controlled Study of Repetitive Transnasal Sphenopalatine Ganglion Blockade with Tx360 as Acute Treatment for Chronic Migraine Headache 55(1): 101-116.

5. Cady RK, Saper J, Dexter K, Cady RJ, Manley HR (2015) Long-Term Efficacy of a Double-Blind Placebo-Controlled, Randomized Study for Repetitive Sphenopalatine Blockade With Bupivacaine vs Saline With the Tx360 Device for Treatment of Chronic Migraine Headache 55(4): 529-542.

6. Khan Sabrina, Jean Schoenen, Messoud Ashina (2014) Sphenopalatine Ganglion Neuromodulation in Migraine: What Is the Rationale? Cephalalgia: an international journal of headache 34(5): 382-391.

7. Lai TH, Fuh JL, Wang SJ (2009) Cranial Autonomic Symptoms in Migraine: Characteristics and Comparison with Cluster Headache. Journal of neurology neurosurgery and psychiatry 80(10): 1116-1119.

8. Yarnitsky, David (2003) Wolff Award: Possible Parasympathetic Contributions to Peripheral and Central Sensitization during Migraine. Headache 43(7): 704-714.

9. Maizels M, Scott B, Cohen W, Chen W (1996) Intranasal lidocaine for treatment of migraine: a randomized, double blind, controlled trial. JAMA 276(4): 319-321.

10. Piagkou M, Demesticha T, Troupis T, Vlasis K, Skandalakis P, et al. (2012) The pterygopalatine ganglion and its role in various pain syndromes: from anatomy to clinical practice. Pain Pract 12(5): 399-412.

11. Jenkins B, Tepper SJ (2011) Neurostimulation for Primary Headache Disorders, Part 1: Pathophysiology and Anatomy, History of Neuromodulation in Headache Treatment, and Review of Peripheral Neuromodulation in Primary Headaches. Headache 51: 1254-1266. 
12. Martelletti P, Jensen RH, Antal A, Arcioni R, Brighina F, et al. (2013) Euro modulation of chronic headaches: position statement from the European Headache Federation. J Headache Pain 14(1): 86.
13. Schoenen J, Jensen RH, Lantéri-Minet M, Láinez MJ, Gaul C, et al. (2013) Stimulation of the sphenopalatine ganglion (SPG) for cluster headache treatment. Pathway CH-1: a randomized, sham-controlled study. Cephalalgia 33(10): 816-830.

\section{Your next submission with Juniper Publishers will reach you the below assets}

- Quality Editorial service

- Swift Peer Review

- Reprints availability

- E-prints Service

- Manuscript Podcast for convenient understanding

- Global attainment for your research

- Manuscript accessibility in different formats

( Pdf, E-pub, Full Text, Audio)

- Unceasing customer service

Track the below URL for one-step submission https://juniperpublishers.com/online-submission.php 